G.EOLOGIC MAP OF THE

TIMBER MOUNTAIN Q UADR $\mathrm{N}$ G $\mathrm{E}$,

N Y E C O U N T Y, N E V A D A

By W. J. Carr and W. D, Quinlivan

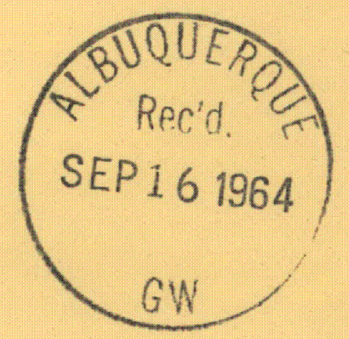

UNITED STATES DEPARTMENT OF THE INTERIOR

GEOLOGICAL SURVEY 

ONITED STATES DEFARTMENT OF THE INTERIOR

GEOLOGICAL SURVEY

\section{GEOLOGIC MAP OF THE TIMBER MOUNTAIN QUADRANGLE, NYE COUNTY, NEVADA*}

By

W. J. Carr and W. D. Quinlivan

September 1964

Report TEI-853

This report is preliminary and has not been edited for conformity with Geological Survey format.

*Prepared on behalf of the U.S. Atomic Energy Commission. 


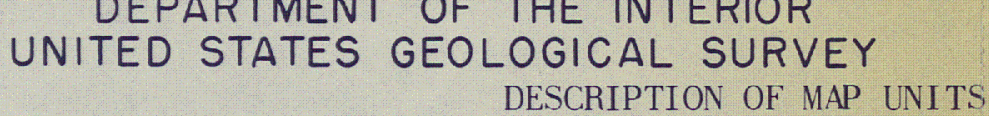

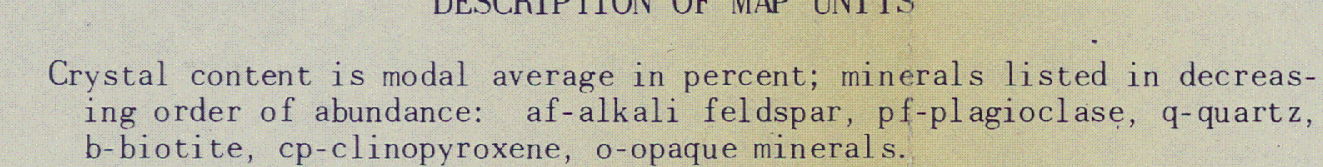

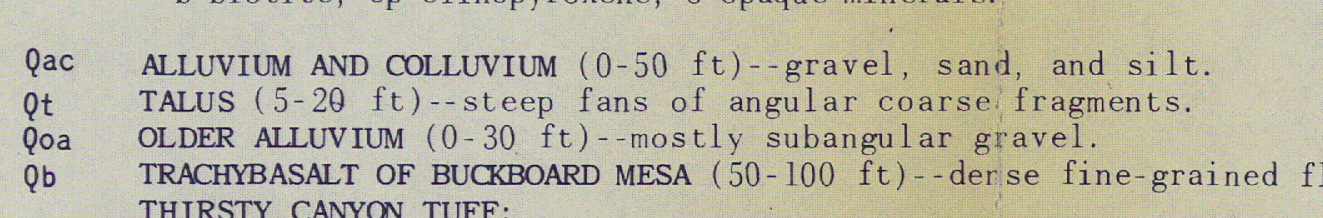

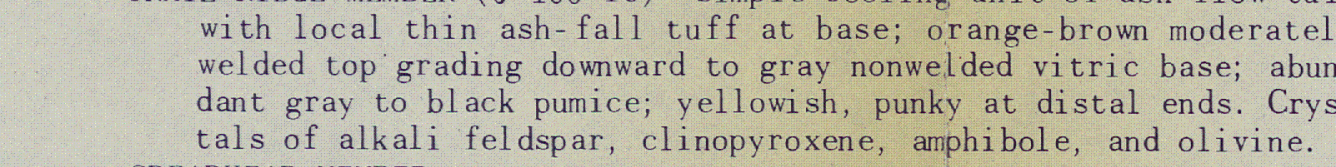

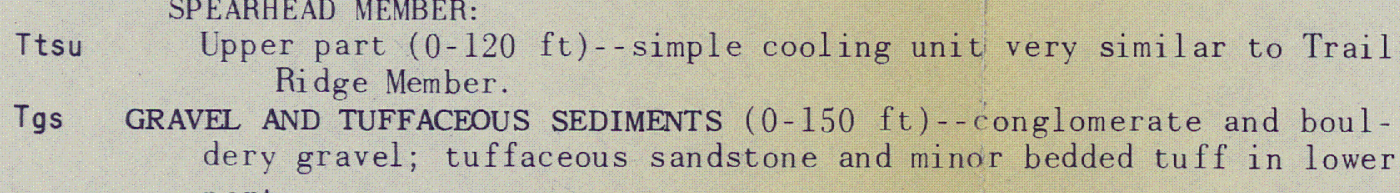

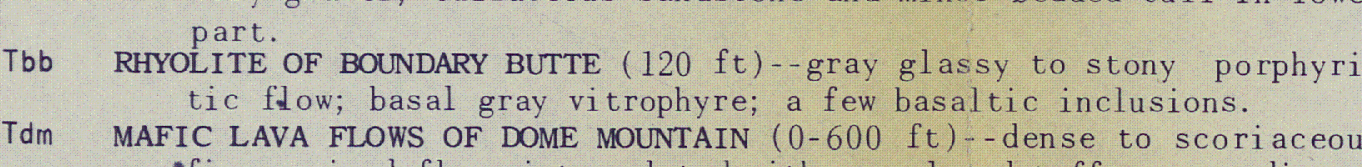

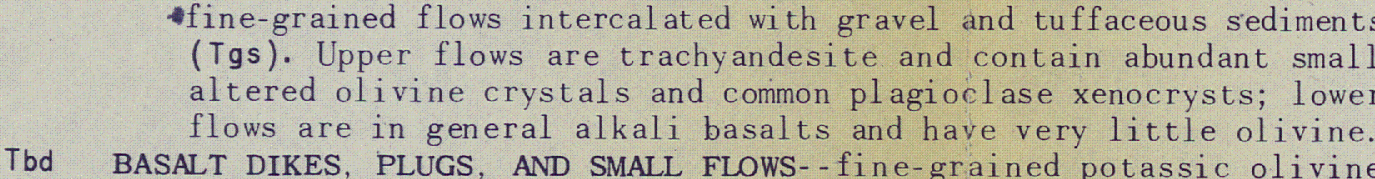

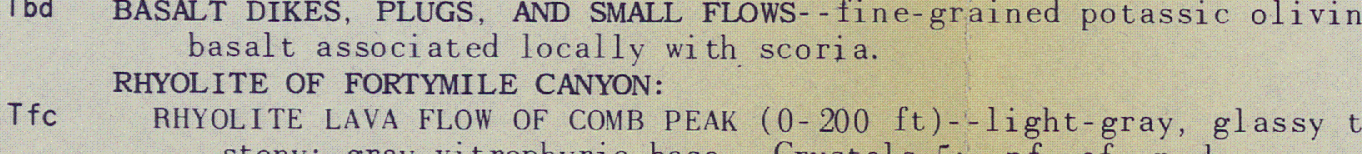

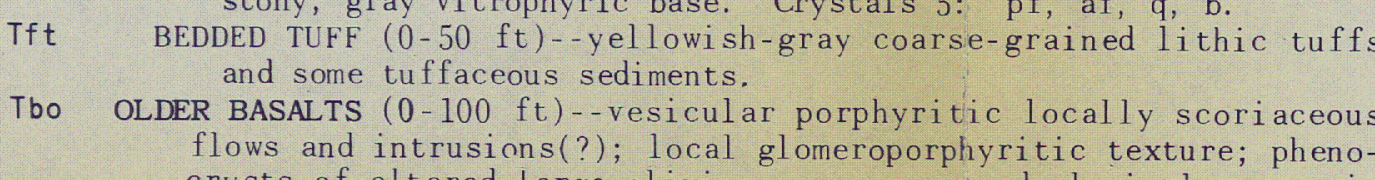

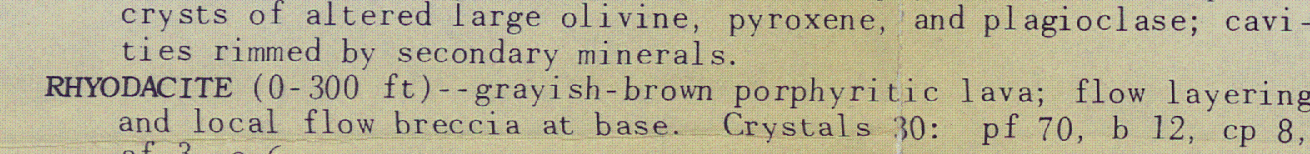

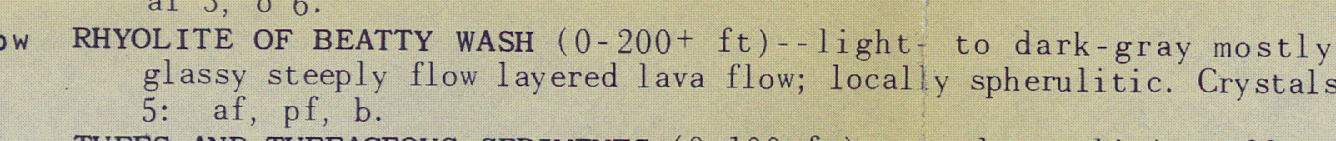

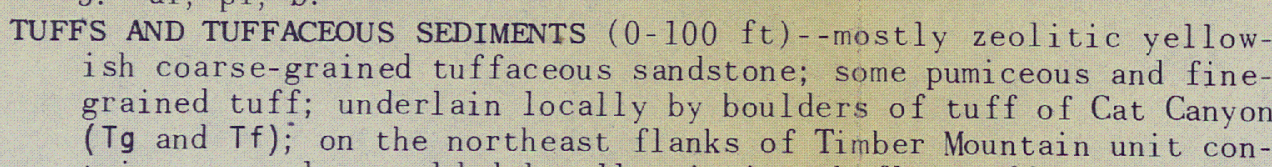

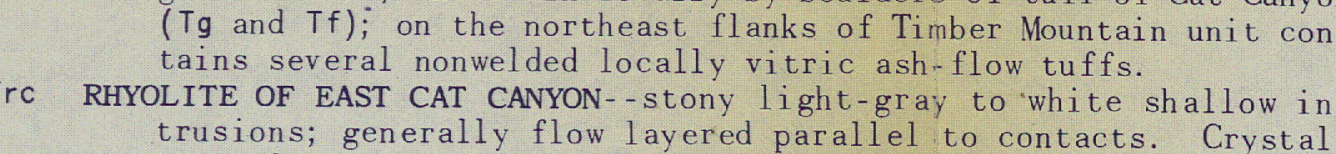

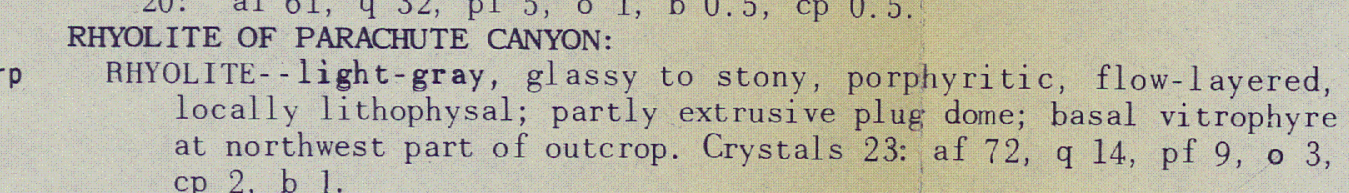

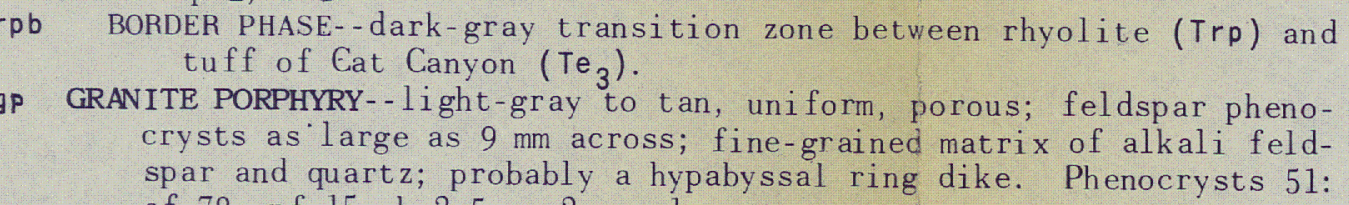

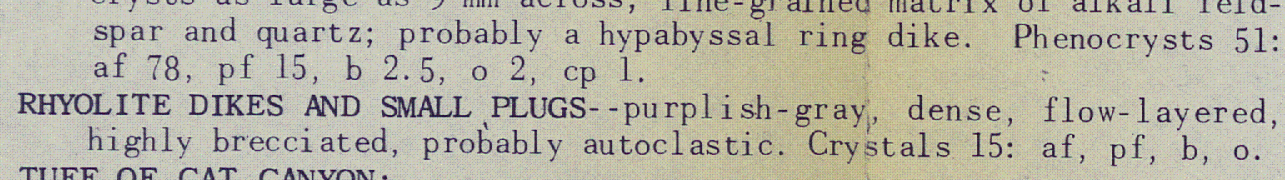

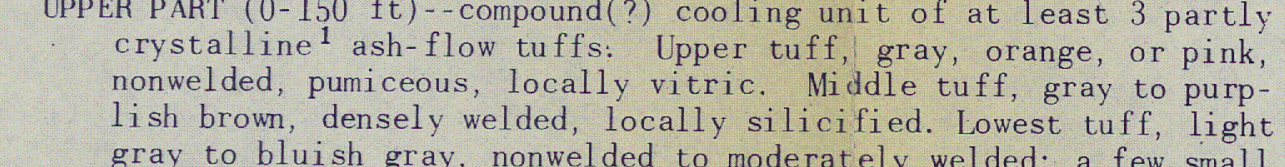

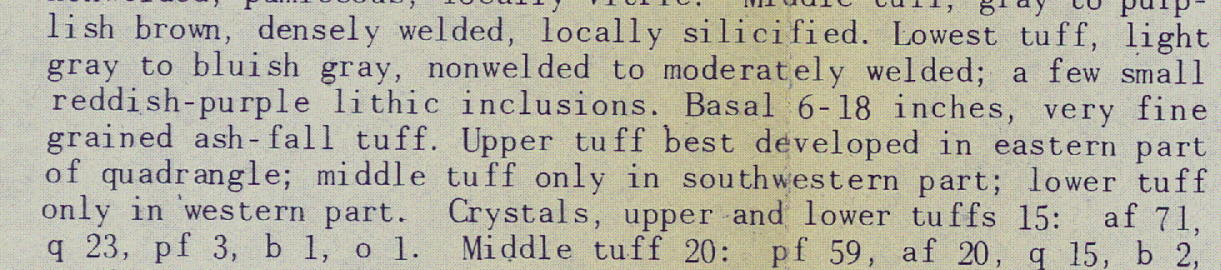

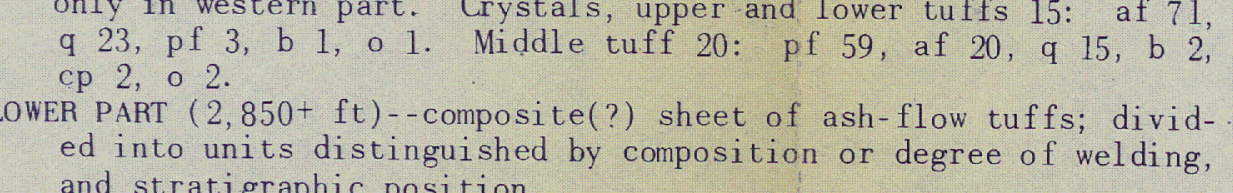

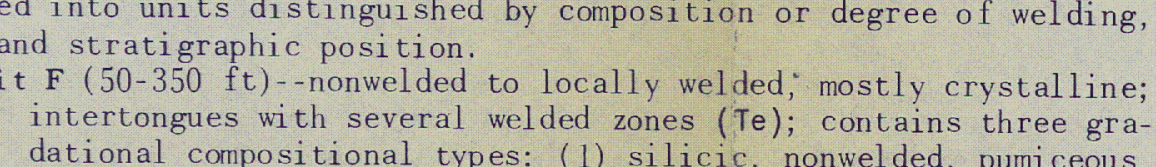

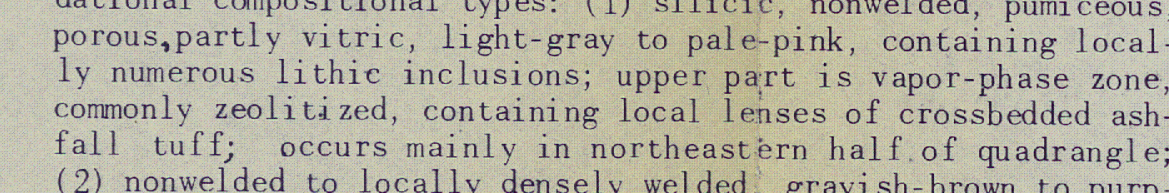

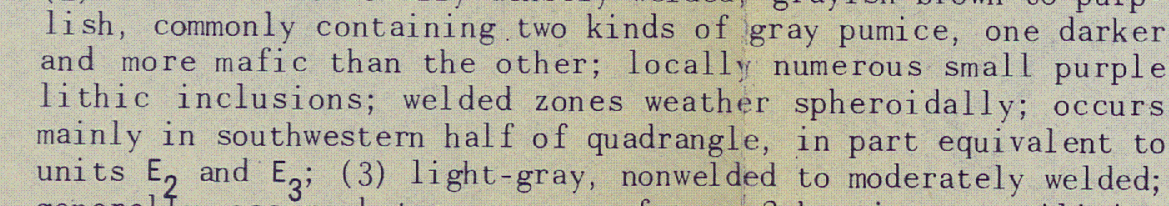

(c)

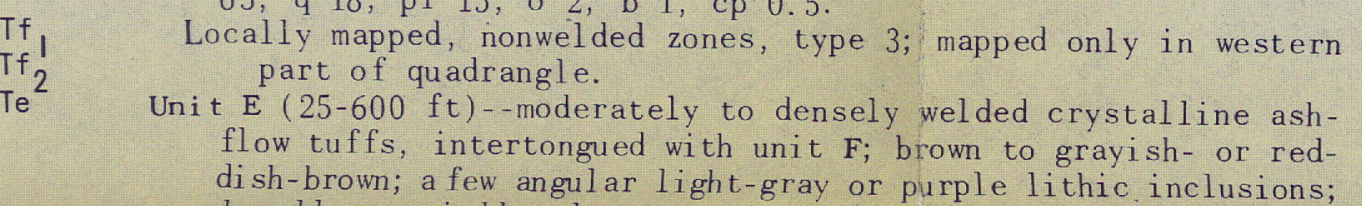

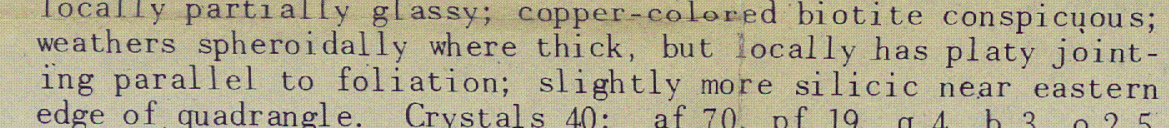

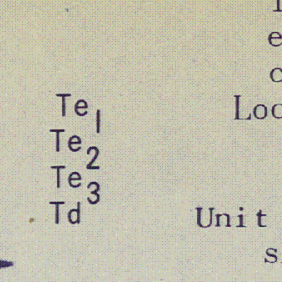

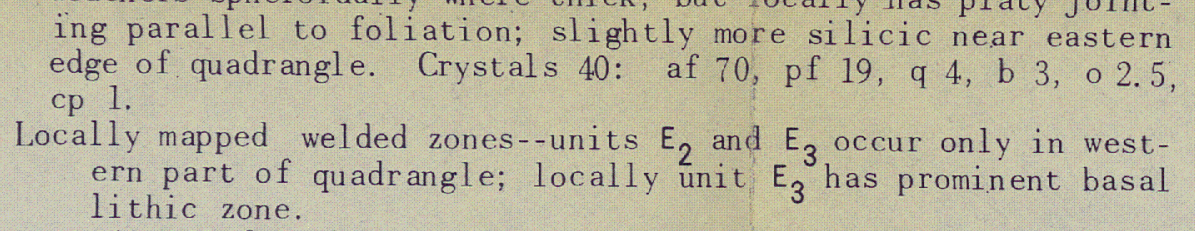

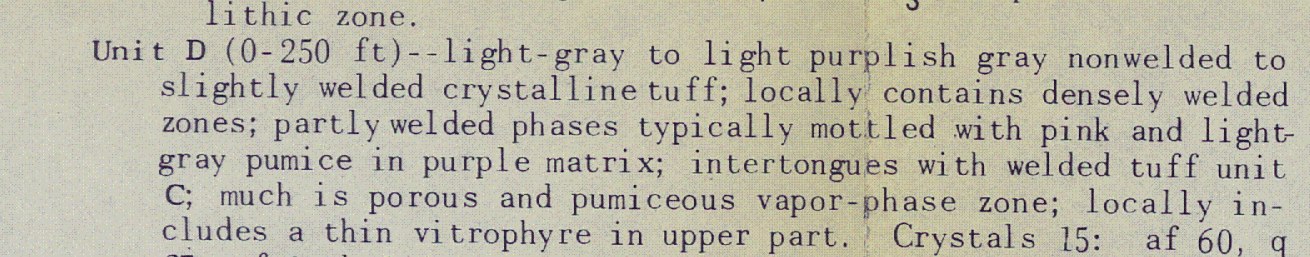

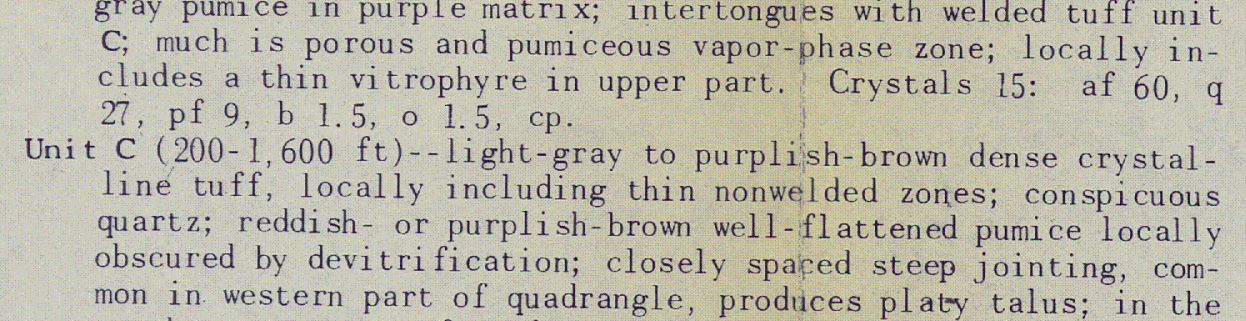

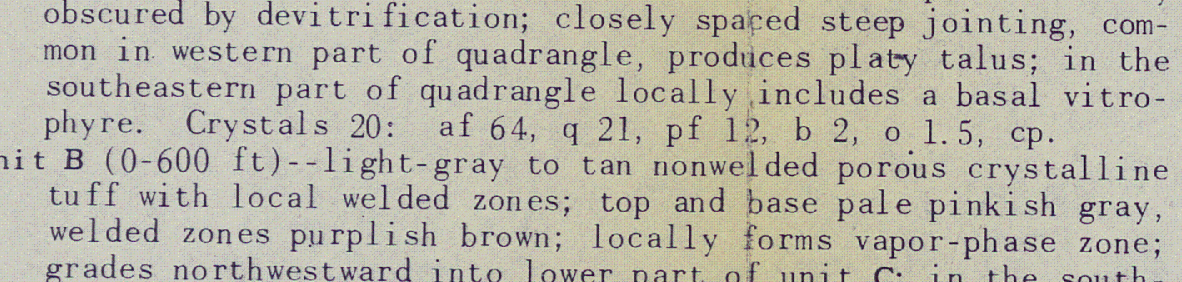

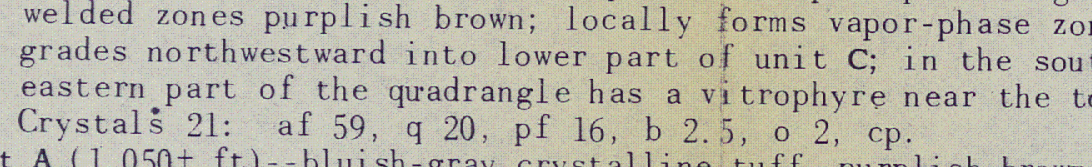

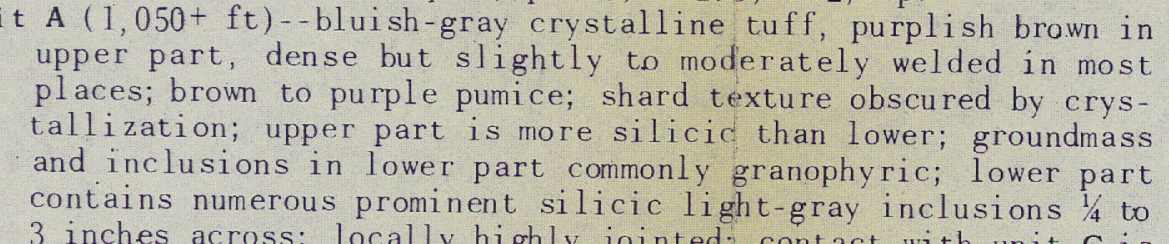

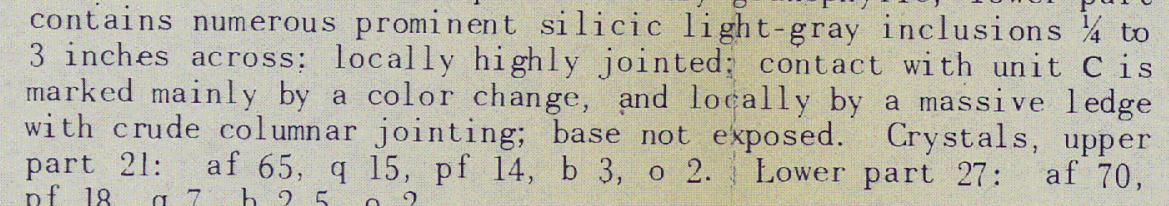

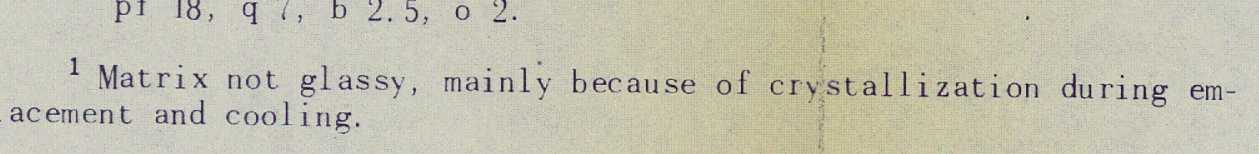

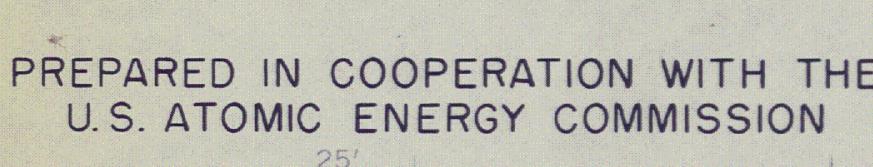

Fint

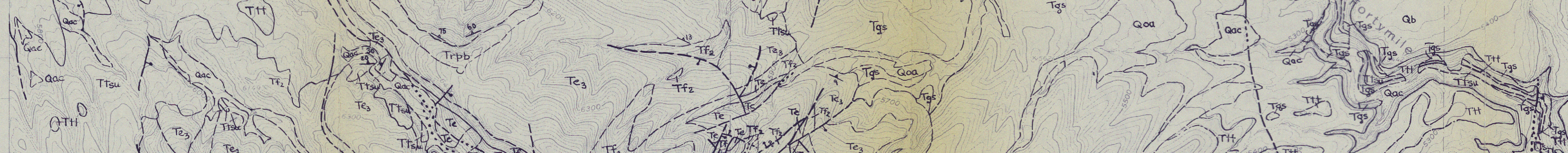

(1) 51 -

1.1 1 (a)

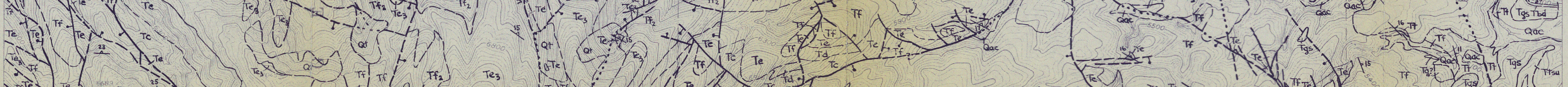
X. $\Rightarrow$ t

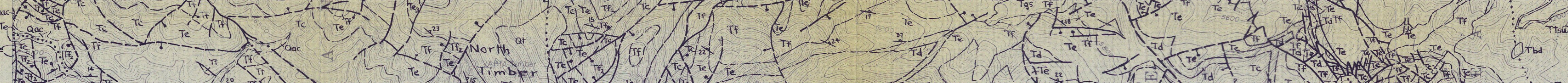
2.

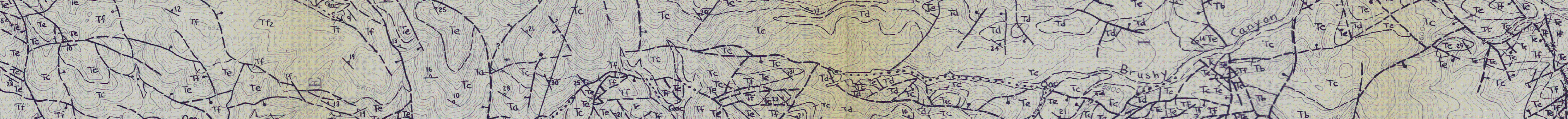

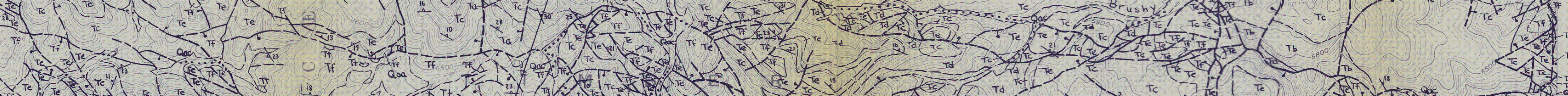

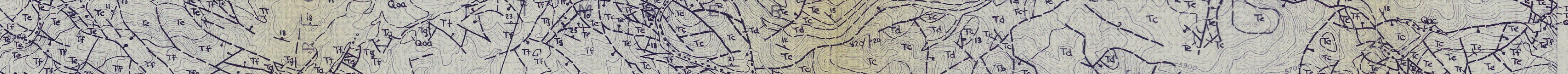
m. 2. - a n a

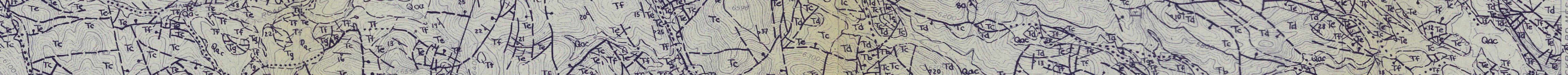
a

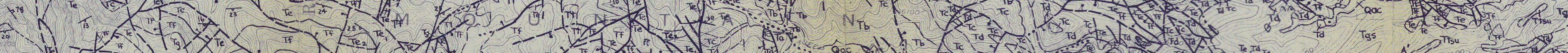

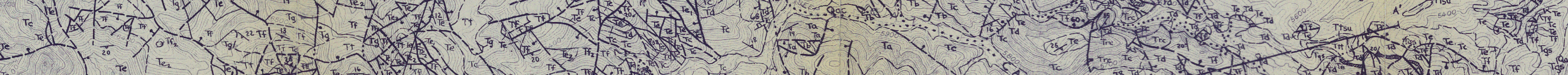

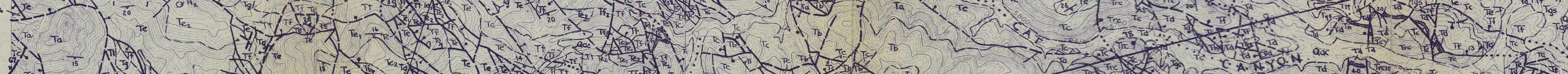
- 5 (20.3

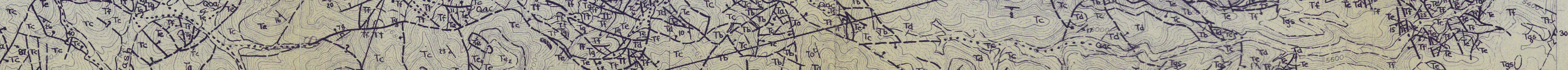

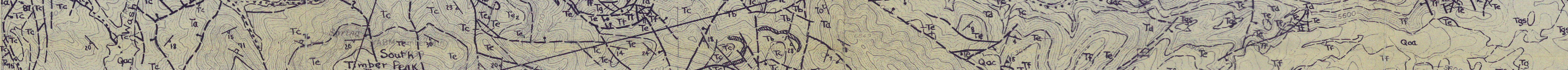

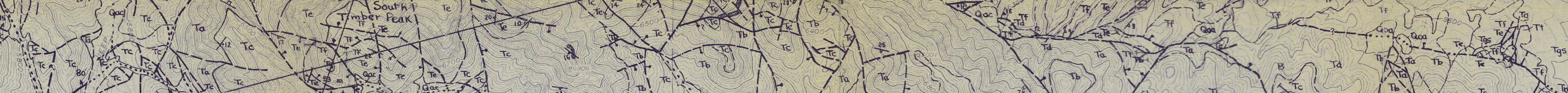

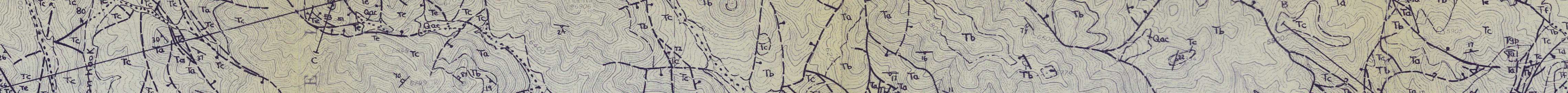
A.

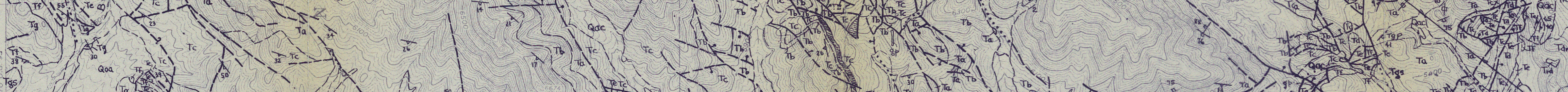

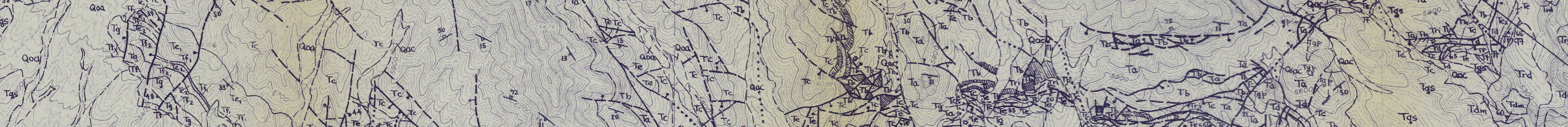

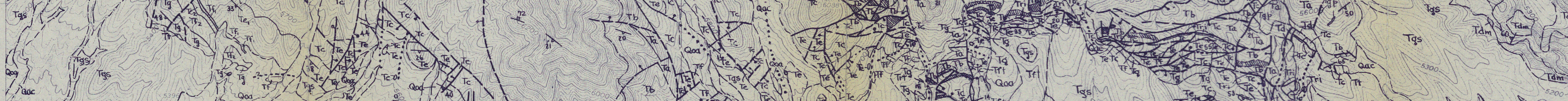
(c)

(1)

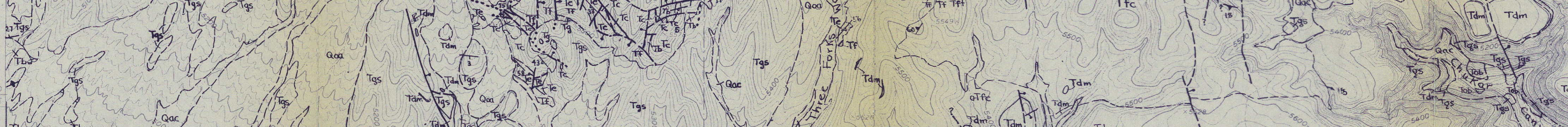

(a)

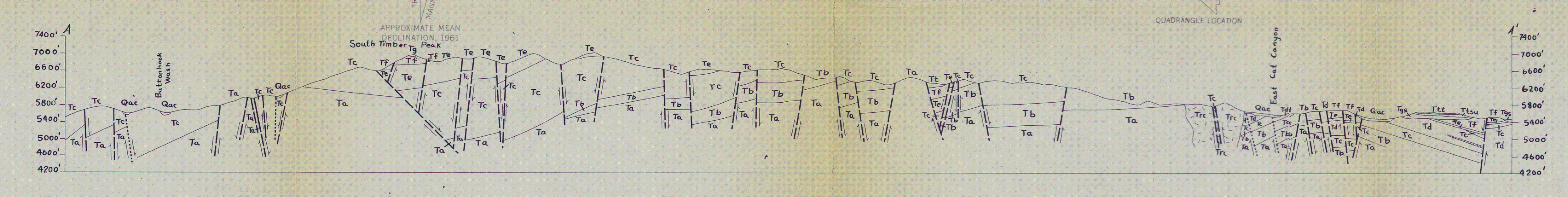

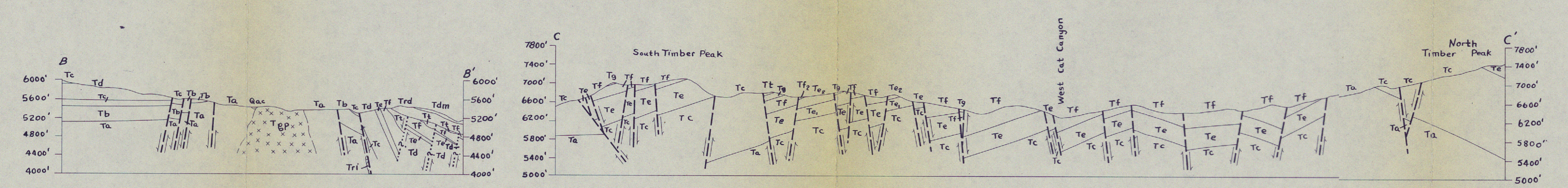

geologic MAP OF THE timBER MOUNTAIN QuAdRANGLE, NYE COUNTY, NEVADA

W.J. Corr ond w. W. Q Quinivivon
1964

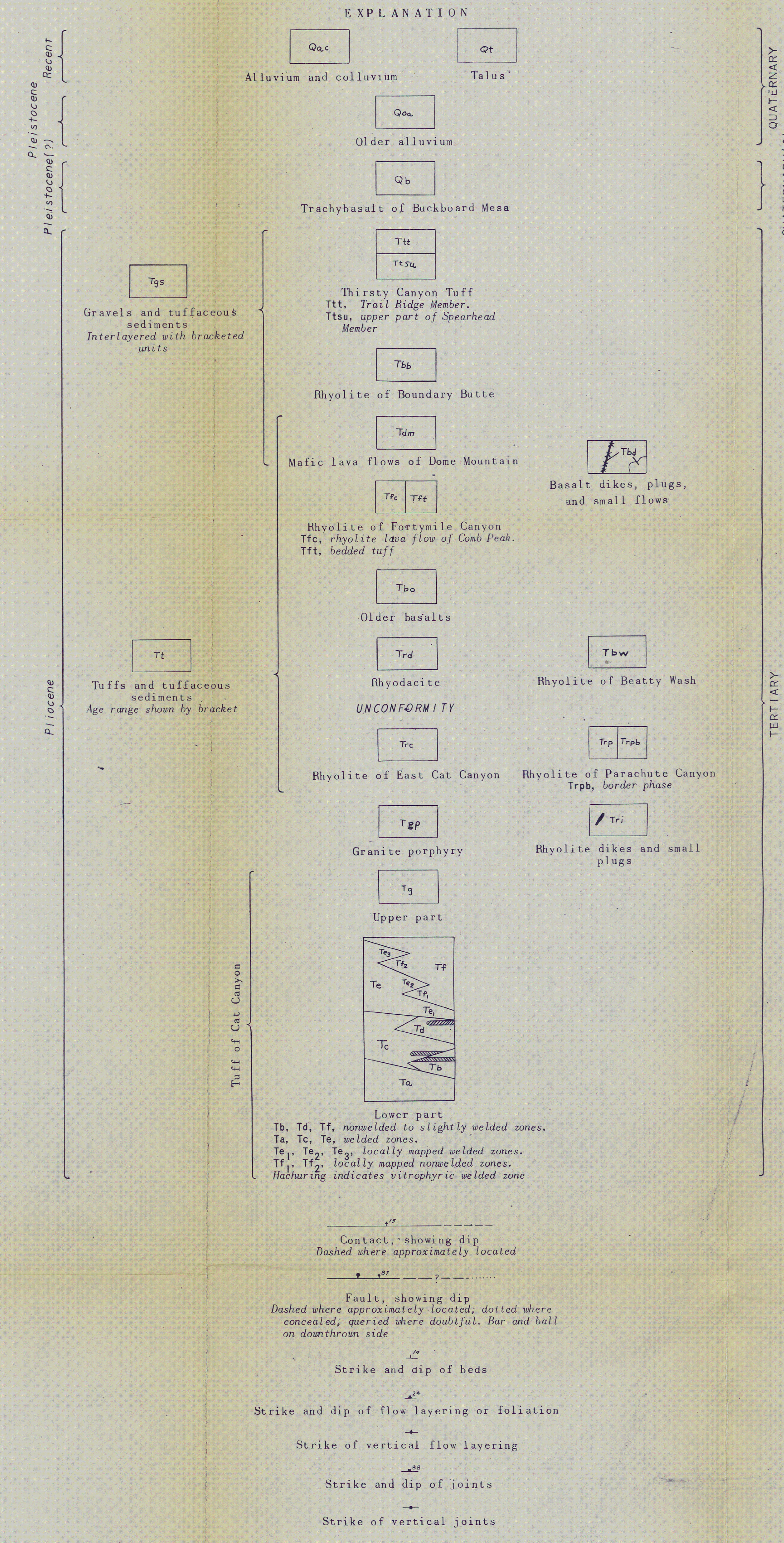

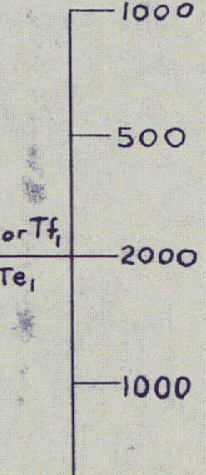

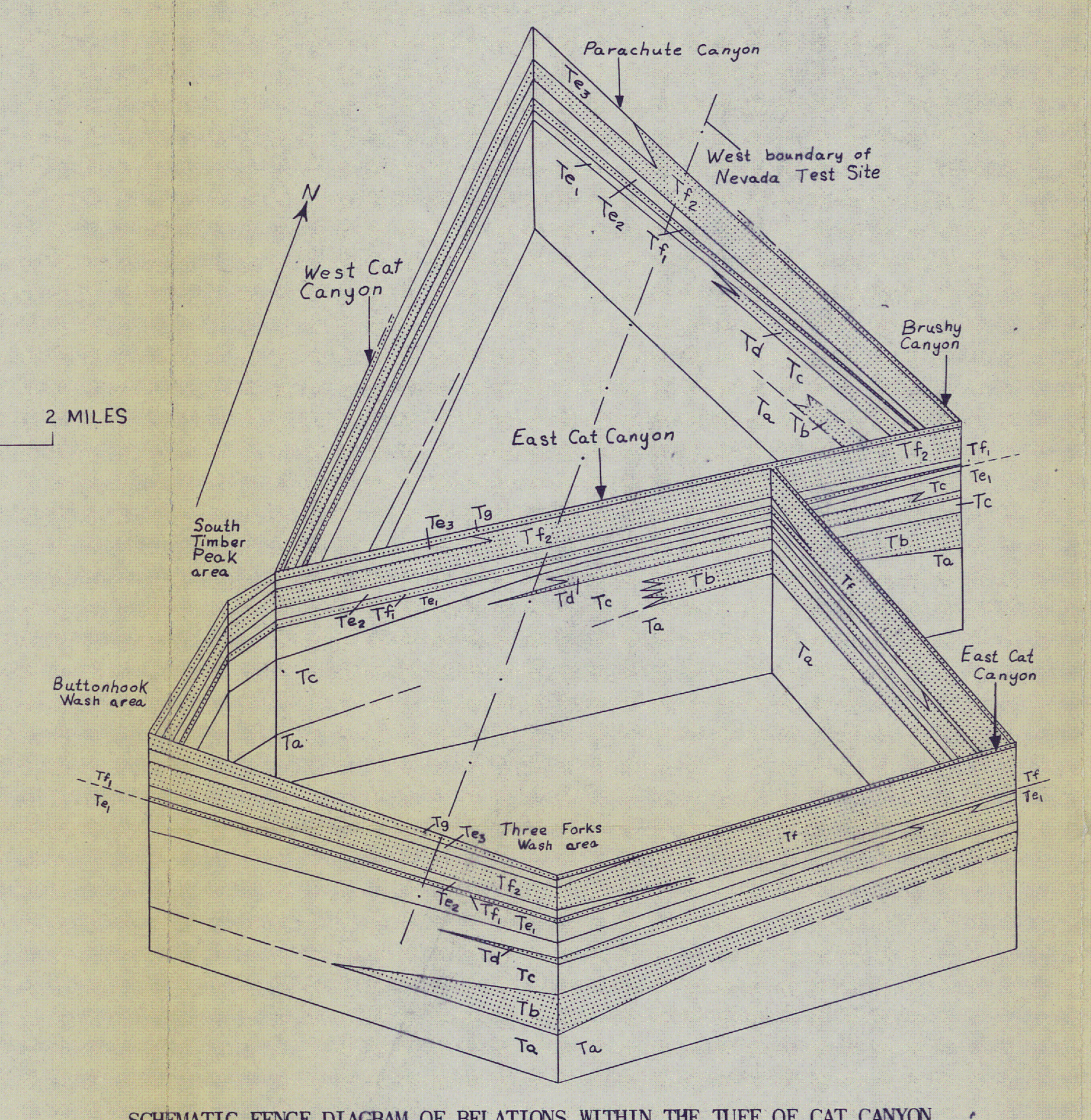

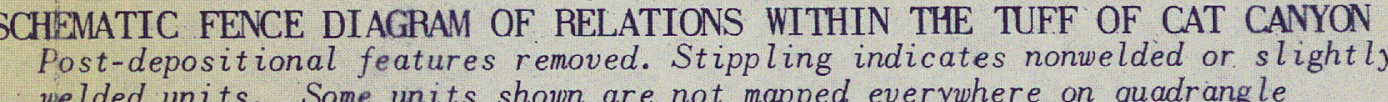

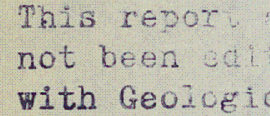

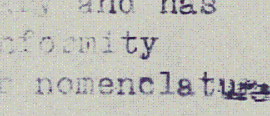



